\title{
What drives the greater or lesser usage of forbearance measures by banks?
}

\author{
Paola De Vincentiis ${ }^{1}$
}

Accepted: 3 September 2020 / Published online: 1 October 2020

(c) The Author(s) 2020

\begin{abstract}
After the subprime crisis, with the worsening of asset quality all around Europe, a lack of harmonization emerged concerning credit classification, monitoring, provisioning and writing-off in the banking industry. A wave of analysis and new regulations by the Supervising Authorities aimed at highlighting best practices and creating a common standard, in order to enhance transparency and accounting data comparability across the European Union. A point of particular attention concerned the usage of forbearance measures and the classification and provisioning of forborne positions. This paper deep-dives into this issue leveraging on the public dataset disclosed by the European Banking Authority, following the 2018 EU-wide Transparency Exercise. The purpose of this paper is twofold. On one side, we want to gauge the extension of the forbearance measures' usage among a sample of major European banks and the drivers of this usage. On the other side, we want to analyze which main factors impact on the loan loss provisioning of forborne positions.
\end{abstract}

Keywords Forbearance measures $\cdot$ Loan loss provisions $\cdot$ Non-performing loans $\cdot$ Asset quality $\cdot$ Collateral $\cdot$ Credit risk

\section{Introduction}

Banks often approve concessions or modifications to previous loan conditions. Some of these modifications are just motivated by commercial reasons and aim to retain clients who would otherwise move to competitors. Other concessions are related to financial difficulties of the borrowers and are technically called forbearance measures. Their objective should be either to prevent or help resolving problematic loans, safeguarding the bank's exposure. A misuse of forbearance measures may be related to disguising non-performing positions, thus avoiding to burden the profit and loss statement with loan loss provisions.

Forbearance measures are the core topic of this research paper. The purpose of our analysis is twofold. On one side, we want to gauge the extension of the forbearance measures' usage among a sample of major European banks that took part to the EU-wide Transparency Exercise undertaken by the European Banking Authority in 2018. We will compare different types of banks and different countries in order to

Paola De Vincentiis

paola.devincentiis@unito.it

1 Department of Management, University of Torino, Torino, Italy understand the drivers that lead to a wider or lesser weight of the forborne exposures as a percentage of the total loan portfolio. Furthermore, we want to analyze which main factors impact on the loan loss provisioning of forborne positions. The final goal of the two analysis is to understand if the forbearance measures are used properly by banks across Europe and if the higher credit risk that is inevitably inherent to forborne positions is well reflected in the level of loan loss provisions. A side purpose is also to gauge if the harmonization effort exerted by European Supervising Authorities reached the goal of smoothing the differences across countries, even though the full effect shall be visible in a few years.

\section{Context and literature review}

The topic of forbearance measures is important and has been studied in the literature from two different points of view: micro and macro.

From a microeconomics perspective, the main questions addressed are: how do banks classify forborne positions and provision them to cover for the expected credit losses? Are forbearance measures used in a proper way by banks, 
i.e., as an instrument to prevent or cure problematic credit exposures?

From a macroeconomics perspective, the issues analyzed are: what are the potential consequences of an extensive usage of forbearance measure on growth and optimal allocation of financial resource? Which are the exogenous factors that may push banks to use forbearance measures more?

The main starting point of the first wave of studies was the subprime crisis which began in 2007 in the USA and had many long lasting effects on the financial and economic environment all over the world. One of these effects was the tremendous worsening of the credit quality of banks' lending portfolios and the consequent increase in the stock of non-performing exposures across Europe [22, 23]. The phenomenon clearly worried the Supervisory Authorities and pushed them to analyze the issue attentively, in order to better evaluate the dimension of the problem and devise potential solutions. In particular, a comprehensive survey was carried out by the Basel Committee for Banking Supervision [8]. What the Supervisors found out during this deepdiving exercise scared them even more. They found out a sort of jungle characterized by a wide range of practices in credit evaluation, classification, monitoring, provisioning and writing-off across different banks and national banking systems. The differences were so huge to prevent the possibility to compare different credit institutions, especially if located in different countries. The Basel Committee for Banking Supervision [8] described the problem in caustic terms: "One of the lessons learnt from the financial crisis is that supervisors and investors could not always understand and compare information about credit categorization presented in banks financial statements. Banks used different (and often undisclosed or insufficiently disclosed) methodologies and assumptions for valuations, provisioning and risk weightings, increasing opacity and reducing comparability for end users."

Among many other aspects, one crucial issue was the different use and treatment of forbearance measures. The general understanding is that forbearance is a change of the contractual terms of a loan motivated by the financial difficulties of the borrower. Given this general definition, there are many details, which can make a dramatic difference on how the operation is granted, valued and represented in the books: which kind of measures qualify as forbearance? A change in the contractual terms of a loan, negotiated with a client who is not in financial difficulty, is to be considered as a forbearance? How shall a forborne exposure be classified: performing, non-performing or should a special different category be used? May a non-performing position be reclassified to performing status as a consequence of the approval of a forbearance measure? How does the approval of a forbearance measure affect the loan loss provisioning of the exposure?
The consequences of different approaches to the abovementioned questions may deeply affect the representation of credit risk exposure. The European Banking Authority [10-16] well remarked: "In the current recessionary economic environment, asset quality has been a concern lately through; (a) the potential misuse of forbearance to avoid the recognition of some losses; (b) the lack of harmonized definition of forbearance and non-performing exposures which prevents meaningful comparisons of asset quality between institutions. [...] This issue also creates uncertainty for the markets: there is no standard against which to compare the soundness of banks' exposures to enable identification of more robust institutions. As a result, the lack of harmonized definitions contributes to the general feeling of distrust regarding the asset quality of European Banks as a whole."

Based on the described findings, the Supervising Authority started a structured harmonization process that gave rise to the issuance, in 2017 and 2018, of various Guidelines, Regulations and Technical Standards, published by the Basel Committee for Banking Supervision [7], the European Banking Authority [10-16] and the European Central Bank [16-19]. In particular, the forbearance measures were a focus of great interest and much effort was devoted to create a clear normative framework for this tool. The features and the classification of forborne positions were described in extreme details, in order to foster a common understanding and to force banks to use this instrument properly.

The specific empirical literature on the drivers of forbearance and provisioning of forborne positions is very limited. To our knowledge, the most exhaustive contribution on the topic is Homar et al. [20]. This paper analyzes the usage of forbearance measure and the coverage of these positions as a function of various elements: macroeconomic variables, quality of banking supervisions, collateral valuation and bank's financial strength.

Moving to the macroeconomic perspective, the activity of loan restructuring and forbearance is a core focus in the literature stream concerning the so-called zombie firms, i.e., firms that should be dead, but are kept alive by banks that extend, modify and restructure their exposures beyond any reasonable expectation of recovery. There is quite substantial evidence that—during the last two decades—a relevant surge in the phenomenon of zombie firms took place in Europe and in other advanced economies [2, 9, 10]. According to Banerjee and Hofmann [4], the increase amounted approximately to 10 percentage points (from 2 to $12 \%$ ) from the late 1980s across 14 developed countries.

The most frequent life-supporting devices for these zombie firms are forbearance measures that are approved by financing banks without duly taking into consideration the viability of the new repayment plan and the realistic possibility for the borrower to continue operating as a going concern. 
Deep-diving into the specific literature on the topic, the first contributions focus on the Japanese market where the zombie firms phenomenon was identified as one of the main root causes of the so-called lost decade.

Moving to the European context, Andrews and Petroulakis [3] show that zombie firms are more likely to be connected to weak banks that are more reluctant to recognize non-performing positions, thus burdening their already fragile income statements. They also find, similarly to Adalet McGowan et al. [1], that the phenomenon is stronger in countries where insolvency regimes and creditors' protection are weaker. Banks, in this context, would have less incentive to adopt hard workout strategies due to the low expected cash flows from recovery.

Storz et al. [24] claim that zombie firms, when associated with weak banks, tend to increase their debt exposure even further. Any policy intervention shall consequently address the deleveraging of both banks and firms.

Our work belongs to the first described stream of the literature, adopting a micro-perspective, and builds on the paper of Homar et al. [20]. What we add is a specific focus on how the forborne positions are classified and the drivers of this classification. The new harmonized rules clarify that a forborne position may classify either performing or non-performing and specify the criteria which should be followed to make this decision. We want to verify if the national context and the bank's financial features matter not only for the extent of forbearance usage-as already emerged in previous literature-but also on the specific classification of these exposures.

\section{Sample description}

The data used throughout the paper belong to the EU-wide Transparency Exercise undertaken by the European Banking Authority (EBA) in 2018. The Exercise comprised 130 major banking institutions from 25 countries and collected data from the consolidated accounts at the 31 December 2017 and the 30 June 2018. Along with a Risk Assessment Report, EBA disclosed the entire database of bank-to-bank information on capital positions, risk exposure amounts and asset quality.

Table 1 presents the structure of the dataset by country and total amount of the loan portfolio. First, we can notice a concentration of the sample in four major countries (Germany, Spain, France and Italy) where over 40 percent of the banks are located and approximately 56 percent of total loan portfolio. Confronting the number of banks and their weight on total loans, it is evident that the United Kingdom-even though represented with a limited number of institutions - covers a relevant quota of lending activity. By adding the share of loans granted by British banks, we reach a coverage of 75 percent. The credit exposure toward nonfinancial companies (last two columns in Table 1) is quite extensive in most countries: 34 percent on average, with peaks above 40 percent in Italy, Austria and Greece. To our goals, this part of the loan portfolio is particularly interesting because the frequency and potential impact of forbearance measures are more relevant.

Table 2 analyzes the lending portfolio quality, the weight of positions with approved forbearance measures and the coverage of loan loss provisions over total carrying amount both for non-performing and forborne positions. First, we can notice that the share of positions with a forbearance measure varies sensibly among the different countries taken into consideration. However, at the first sight, the phenomenon seems strictly related to the amount of non-performing loans. Apparently, a change in contractual terms is quite a standard tool to face transitory or structural financial difficulties of the borrowers. The correlation between the NPL and forborne ratio, on a bank-by-bank basis, is very high and amounts to 0,88 .

On the contrary, what is quite varied is the share of forborne positions that is classified as non-performing. It is worth to remind here that, even according to the new harmonized framework, banks can maintain a position performing, after approving a forbearance measure, if there are good chances that the borrower will be able to comply regularly, according to the new contractual arrangement. However, it is not possible to upgrade a position to performing status as a mere consequence of the forbearance measure, because a probing period has to pass and some conditions need to be fulfilled before doing so. The data shown in Table 2 seem to indicate that either the compliance to the new harmonized rules is still incomplete or the prevailing interpretation in quite varied on a national basis. The proportion of forborne exposures classified as non-performing goes from levels above the 80 percent in Greece, Poland, Hungary and Bulgaria to levels below 40 per cent in Norway and Finland.

Finally, Table 2 shows that the coverage of forborne positions is quite substantial and close to that of the non-performing portfolio. Such an evidence is fully coherent to the fact that the approval of a forbearance measure ultimately indicates a situation of financial difficulty and the need to find a solution either to overcome a non-performing status or to prevent it. Even with this general evidence, the last column of Table 2 shows that the gap of coverage between non-performing and forborne portfolio varies significantly from country to country. The analysis that follows aims to deepen the understanding of the phenomenon and the drivers underpinning the loan loss provisioning. 
Table 1 Sample distribution by country and total loan portfolio (31 December 2017)

\begin{tabular}{|c|c|c|c|c|c|c|}
\hline \multirow[t]{2}{*}{ Countries } & \multicolumn{2}{|c|}{ Banks in the sample } & \multicolumn{2}{|l|}{ Total loans } & \multicolumn{2}{|c|}{$\begin{array}{l}\text { Loans to non-financial } \\
\text { corporations }\end{array}$} \\
\hline & $\#$ & $\%$ & Mln Eur & $\%$ & Mln Eur & $\%$ \\
\hline Germany & 20 & 15.38 & $2,571,584$ & 13.02 & 744,672 & 28.96 \\
\hline Spain & 12 & 9.23 & $2,346,998$ & 11.88 & 696,405 & 29.67 \\
\hline France & 11 & 8.46 & $4,322,327$ & 21.89 & $1,352,937$ & 31.30 \\
\hline Italy & 11 & 8.46 & $1,677,558$ & 8.49 & 747,119 & 44.54 \\
\hline Sweden & 7 & 5.38 & $1,017,531$ & 5.15 & 381,168 & 37.46 \\
\hline Austria & 6 & 4.62 & 372,941 & 1.89 & 153,725 & 41.22 \\
\hline Belgium & 6 & 4.62 & 452,117 & 2.29 & 111,191 & 24.59 \\
\hline Netherlands & 6 & 4.62 & $1,639,899$ & 8.30 & 563,359 & 34.35 \\
\hline UK & 6 & 4.62 & $3,647,401$ & 18.47 & 870,403 & 23.86 \\
\hline Luxembourg & 5 & 3.85 & 21,529 & 0.11 & 529 & 2.46 \\
\hline Portugal & 5 & 3.85 & 178,760 & 0.91 & 67,009 & 37.49 \\
\hline Denmark & 4 & 3.08 & 550,790 & 2.79 & 171,129 & 31.07 \\
\hline Greece & 4 & 3.08 & 224,435 & 1.14 & 105,683 & 47.09 \\
\hline Ireland & 4 & 3.08 & 197,356 & 1.00 & 63,898 & 32.38 \\
\hline Ciprus & 3 & 2.31 & 29,151 & 0.15 & 12,752 & 43.74 \\
\hline Iceland & 3 & 2.31 & 22,513 & 0.11 & 10,674 & 47.41 \\
\hline Malta & 3 & 2.31 & 9927 & 0.05 & 2734 & 27.54 \\
\hline Norway & 3 & 2.31 & 198,047 & 1.00 & 77,635 & 39.20 \\
\hline Slovenia & 3 & 2.31 & 15,095 & 0.08 & 5517 & 36.55 \\
\hline Finland & 2 & 1.54 & 122,555 & 0.62 & 41,393 & 33.78 \\
\hline Poland & 2 & 1.54 & 85,672 & 0.43 & 25,686 & 29.98 \\
\hline Bulgaria & 1 & 0.77 & 3631 & 0.02 & 2106 & 58.00 \\
\hline Estonia & 1 & 0.77 & 1705 & 0.01 & 470 & 27.55 \\
\hline Hungary & 1 & 0.77 & 29,292 & 0.15 & 9077 & 30.99 \\
\hline Romania & 1 & 0.77 & 9195 & 0.05 & 3095 & 33.66 \\
\hline Total EU & 130 & 100 & $19,748,011$ & 100 & $6,220,366$ & 31 \\
\hline Average & 10 & 7.69 & $1,519,077$ & 7.69 & 478,489 & 34.07 \\
\hline Stand. Dev. & 4.37 & 3.36 & $1,222,698$ & 6.19 & 364,835 & 10.41 \\
\hline Max & 20 & 15.38 & $4,332,327$ & 21.89 & $1,352,937$ & 58.00 \\
\hline Min & 1 & 0.77 & 1705 & 0.01 & 470 & 2.46 \\
\hline
\end{tabular}

\section{Methodology}

After the qualitative description of the phenomenon presented so far, we want to explore more in depth the usage of forbearance measures and the loan loss provisioning associated with these concessions. In particular, we want to address three main research questions.

\section{First question: Which are the drivers that lead to a wider or lesser usage of forbearance measures by different banks?}

The dependent variable in this analysis is the FORB_RATIO, which is the proportion of positions with an approved forbearance measure over the total carrying amount of loans to non-financial corporations. We assume that a higher weight of non-performing positions may push the bank to try and solve the situation by rescheduling the debt or otherwise modifying the original terms of the contract. Thus, we expect a positive sign for the regressor NPL_RATIO. We then want to check if banks characterized by a larger loan portfolio and/or by a higher exposure to small-medium companies tend to use more frequently the forbearance measures. We expect larger banks to have a richer set of tools to manage the non-performing portfolio, which could reduce the recourse to forbearance. As the set of workout strategy available and actively used could increase more than proportionally with the dimension of the bank, we use the natural logarithm of total assets as a regressor and we expect a negative sign. Likewise, we expect a larger share of SME's loans to be related to a lower frequency of forbearance, since the smaller dimension of single exposures will discourage the administrative burden of a renegotiation and push toward portfolio solutions, based for instance 
Table 2 Loan portfolio's quality, forbearance measures and loan loss provisions ( 31 December 2017)

\begin{tabular}{|c|c|c|c|c|c|c|}
\hline Countries & NPL ratio (\%) & $\begin{array}{l}\text { Forborne } \\
\text { ratio (\%) }\end{array}$ & $\begin{array}{l}\text { Non-perform- } \\
\text { ing forborne } \\
(\%)\end{array}$ & $\begin{array}{l}\text { Coverage } \\
\text { NPL (\%) }\end{array}$ & $\begin{array}{l}\text { Coverage } \\
\text { forborne }(\%)\end{array}$ & $\begin{array}{l}\text { Coverage gap } \\
\text { NPL_-forborne } \\
(\%)\end{array}$ \\
\hline Germany & 5.06 & 4.53 & 74.38 & 44.86 & 32.85 & 12.02 \\
\hline Spain & 7.82 & 7.71 & 61.86 & 50.19 & 31.47 & 18.73 \\
\hline France & 5.16 & 1.80 & 69.42 & 52.89 & 31.95 & 20.93 \\
\hline Italy & 18.42 & 7.83 & 73.71 & 51.36 & 29.58 & 21.77 \\
\hline Sweden & 1.83 & 2.33 & 51.78 & 34.62 & 15.86 & 18.76 \\
\hline Austria & 5.97 & 4.08 & 69.79 & 50.42 & 35.19 & 15.23 \\
\hline Belgium & 5.50 & 2.92 & 68.85 & 51.34 & 34.01 & 17.33 \\
\hline Netherlands & 4.89 & 4.18 & 62.38 & 30.17 & 18.44 & 11.73 \\
\hline UK & 3.08 & 2.16 & 68.35 & 43.14 & 25.01 & 18.13 \\
\hline Luxembourg & 1.61 & 0.02 & 0.00 & 43.27 & 0.00 & 43.27 \\
\hline Portugal & 29.60 & 20.17 & 76.67 & 53.70 & 40.33 & 13.37 \\
\hline Denmark & 4.03 & 3.06 & 58.04 & 24.84 & 17.56 & 7.28 \\
\hline Greece & 51.41 & 22.81 & 82.53 & 50.34 & 33.45 & 16.89 \\
\hline Ireland & 13.72 & 10.26 & 74.84 & 31.64 & 25.52 & 6.12 \\
\hline Cyprus & 49.33 & 36.41 & 72.08 & 48.96 & 28.64 & 20.31 \\
\hline Iceland & 3.69 & 6.37 & 40.11 & 44.22 & 16.38 & 27.84 \\
\hline Malta & 8.73 & 7.48 & 64.21 & 43.59 & 25.65 & 17.95 \\
\hline Norway & 3.80 & 7.14 & 33.04 & 34.18 & 8.18 & 26.00 \\
\hline Slovenia & 25.69 & 19.03 & 84.96 & 63.68 & 53.71 & 9.97 \\
\hline Finland & 1.89 & 1.01 & 38.08 & 42.48 & 9.27 & 33.21 \\
\hline Poland & 10.49 & 4.71 & 84.11 & 50.39 & 36.07 & 14.32 \\
\hline Bulgaria & 25.29 & 18.55 & 87.38 & 45.56 & 42.81 & 2.74 \\
\hline Estonia & 3.00 & 0.00 & NA & 20.61 & NA & NA \\
\hline Hungary & 14.79 & 7.64 & 81.73 & 55.76 & 50.54 & 5.22 \\
\hline Romania & 13.23 & 10.45 & 76.09 & 56.80 & 45.09 & 11.71 \\
\hline TotalEU & 7.77 & 4.75 & 69.04 & 48.14 & 29.29 & 18.85 \\
\hline Mean & 12.53 & 8.36 & 64.94 & 44.89 & 28.67 & 17.19 \\
\hline SD & 13.83 & 8.66 & 20.13 & 10.39 & 13.34 & 9.13 \\
\hline Max & 51.41 & 36.41 & 87.38 & 63.68 & 53.71 & 43.27 \\
\hline Min & 1.61 & 0.00 & 0.00 & 20.61 & 0.00 & 2.74 \\
\hline
\end{tabular}

on the sale of non-performing exposures. Finally, based on the results of the survey carried out by the Bank for International Settlement [5], we expect a different frequency of forborne positions on a country basis, based also on the local normative framework that may make the tools more or less attractive for the banks. In particular, we control through specific dummies the effect of the bank being located in Italy, France, Germany, Spain and Great Britain. We do not consider individually other countries because of the limited number of banks in the sample. In line with Homar et al. [20], we expect to find a higher percentage of forborne positions in countries characterized by lax bank supervision. We control for a set of macroeconomic parameters for each country in the dataset, including the growth rate of GDP and the SME's value added, as a proxy of the relevance of small and medium enterprises in the country where the bank's headquarters are located. All indicators are 1-year lagged, at 31 December 2016, since the effect of a changing economic environment over credit portfolios and resulting banking strategies would reasonably not be immediate. We expect a wider usage of forbearance measures when the economy is growing at a faster speed. In fact, in such a context, more time and flexibility allowed to the problematic clients could result in a higher recovery rate or in a full resolution of a temporary difficulties. We expect forbearance measures to be less common in countries characterized by a wider presence of small and medium enterprises. The "culture" of using such concessions could be relatively more diffused in countries where the average dimension of companies and credit exposures is larger. Finally, we control for the strength of legal protection of creditors rights, which could reasonably influence the choice of alternative workout strategies. To this end, we use the Strength of legal right index computed annually by the World Bank, on a scale from 1 to 12 . The empirical evidence emerged in the "zombie firms" literature points to the fact that lower legal protection of creditors increases 
the tendency to prolong agonies through unjustified concessions and restructuring measures. We thus expect a negative sign for this regressor.

$$
\begin{aligned}
\text { FORB }_{\text {RATIO }}= & \beta_{0}+\beta_{1} \times \mathrm{NPL}_{\mathrm{RATIO}}+\beta_{2} \times \mathrm{LOG}_{\mathrm{LOANS}} \\
& +\beta_{3} \times \mathrm{SME}_{\mathrm{LOANS}}+\beta_{4} \times D_{\mathrm{COUNTRIES}}
\end{aligned}
$$

\section{Second question: Which are the drivers that lead banks to classify forborne positions as non-performing to a wider or lesser extent?}

The dependent variable in the second analysis is FORB NPL, which is the percentage of forborne positions classified as non-performing. In this second analysis, the core aspect is the effect of location, i.e., the country dummies. Different national practices and stance by the supervisors could have an effect on the more or less prudent classification of forborne positions. We control for the FORB_RATIO, the NPL_RATIO and the interaction between the two. We expect a positive sign for the regressor NPL_RATIO, since a lower asset quality of the bank will most probably reflect in a lower asset quality of the forborne portfolio. On the contrary, we expect a negative sign for the regressor FORB_RATIO. In fact, when the forbearance measure is more frequent, they are most probably used both as a strategy to manage nonperforming exposures and as a precautionary tool aimed at preventing a borrower from becoming non-performing. In this latter case, the positions may well remain in bonis even after the approval of the concession. Finally, the interaction between the NPL_RATIO and the FORB_RATIO aims to check if banks burdened by a higher level of non-performing positions tend to use more frequently the forbearance measures as a tool to prevent or delay the recognition of new problematic assets. The expected sign of the interaction is negative, since banks with a lower loan portfolio quality would tend to keep as much as possible the forborne positions into the performing category. We deem, in this second research question, the macroeconomic controls to be less relevant. On the contrary, we include the Strength of legal right index since the decision to classify a forborne position as performing or non-performing could also be influenced by bank's trust in the possibility to recover the money through enforcement actions. The expected sign of the regressor is positive: the stronger the legal protection of creditors, the stronger the actions that will be taken by bank and consequently the higher the probability that positions will be timely classified as non-performing, starting the consequent workout actions.

$$
\begin{aligned}
\text { FORB }_{\text {NPL }}= & \beta_{0}+\beta_{1} \times D_{\text {COUNTRIES }}+\beta_{2} \times \text { FORB }_{\text {RATIO }} \\
& +\beta_{3} \times \mathrm{NPL}+\beta_{4} \mathrm{NPL} \times \text { FORBORNE }
\end{aligned}
$$

Third question: Which are the drivers that affect the impairment level of forborne positions?

Ultimately, the approval of a forbearance measure points toward an increased riskiness of the borrower. Thus, the loan loss provisions should be substantial on this kind of exposure, which would typically belong to Stage 2 according to IFRS9 accounting standard. In this third analysis, the dependent variable is IMPAIR_FORB that is the percentage impairment on the gross carrying amount of forborne positions. First, we expect the percentage coverage to be positively associated with the FORB_NPL variable. In fact, the amount of loan loss provisions should be higher for forborne exposures classified as non-performing. Second, we expect the impairment level to be negatively correlated with the amount of collateral assisting forborne positions. In fact, the collateral reduces the expected credit loss on the exposures and thus justifies a lower level of provisions. Finally, we control for the effect of LOAN_SME variable. Since the exposures toward small and medium enterprises present in general higher credit risk, we expect a positive sign for the regressor, i.e., a higher coverage through loan loss provisions. We include the macroeconomic controls to account for any difference in coverage policies related to national economic environment.

$$
\begin{aligned}
\mathrm{IMPAIR}_{\mathrm{FORB}}= & \beta_{0}+\beta_{1} \times \mathrm{FORB}_{\mathrm{NPL}}+\beta_{2} \times \mathrm{COLL}_{\mathrm{FORB}} \\
+ & \beta_{3} \times \mathrm{LOANS}_{\mathrm{SME}}+\beta_{4} \times \text { Macroeconomic Controls }
\end{aligned}
$$

Table 3 summarizes the independent variables used in the analysis and the expected sign of each regressor in the framework of the three aforementioned research angles. As well remarked by Klees [21], the choice of variables to include in econometric analysis such as ours is always somewhat subjective and discretionary. There may always be an observed factor which bears on the phenomenon and that is not well captured. However, to the best of our knowledge, we deem that the main drivers are well represented in our analysis, both at country level and at bank-specific level, even tough with a parsimonious approach.

\section{Results}

Table 4 reports the results concerning the first research question. Both regressions show a strong correlation between NPL ratio and forborne ratio. Thus, it is clear that the forbearance measures are quite a standard strategy to manage the financial difficulty of borrowers, before dismissing or writing-off the position. So, when non-performing loans increase, in parallel forborne positions tend to increase. On the contrary, the usage of this strategy as a preventive tool is less common. A prevailing precautionary nature would 
Table 3 Independent variables: definition and expected signs

\begin{tabular}{|c|c|c|c|c|}
\hline \multirow[t]{2}{*}{ Name } & \multirow[t]{2}{*}{ Definition } & \multicolumn{3}{|l|}{ Expected sign } \\
\hline & & Regression 1 & Regression 2 & $\overline{\text { Regression } 3}$ \\
\hline NPL & $\begin{array}{l}\text { Percentage non-performing loans on total carrying amount of the portfolio of } \\
\text { loans to non-financial corporations }\end{array}$ & + & + & \\
\hline LOG_ASSET & Natural logarithm of bank's total asset & - & & \\
\hline LOANS_SME & $\begin{array}{l}\text { Percentage of loans to SMEs on total portfolio of loans to non-financial } \\
\text { corporations }\end{array}$ & + & & + \\
\hline FORB_RATIO & $\begin{array}{l}\text { Percentage of exposures with an approved forbearance measure on the total } \\
\text { carrying amount of the portfolio of loans to non-financial corporations }\end{array}$ & & - & \\
\hline FORB_NPL & $\begin{array}{l}\text { Percentage of exposures with an approved forbearance measure that are classi- } \\
\text { fied as non-performing }\end{array}$ & & & + \\
\hline COLL_FORB & $\begin{array}{l}\text { Collateral available in percentage of total carrying amount for forborne expo- } \\
\text { sures }\end{array}$ & & & - \\
\hline GROWTH_GDP & $\begin{array}{l}\text { 1-year lagged growth rate of GDP (2016) in the country where the bank's } \\
\text { headquarter is located }\end{array}$ & + & & - \\
\hline SME_VA & $\begin{array}{l}\text { 1-year lagged percentage of GDP created by SMEs (2016) in the country } \\
\text { where the bank's headquarter is located }\end{array}$ & - & & + \\
\hline CREDIT_PROTEC & $\begin{array}{l}\text { 1-year World Bank Strength of legal rights index (2016) in the country where } \\
\text { the bank's headquarter is located }\end{array}$ & - & + & \\
\hline
\end{tabular}

in fact lead to a negative correlation between forborne ratio and NPL ratio.

The analysis shows no significant correlation between the forborne ratio and the dimension of the bank, measured by the logarithm of total asset, in contrast with what we were expecting. Apparently, larger banks make an intensive use of forbearance measures, even though they could in principle access to a richer set of strategies and tools to manage their non-performing portfolio. No significant link emerges either between the retail dimension of the loan portfolio and the forborne ratio. Among the macroeconomic controls, as we were expecting, the usage of forbearance measures is wider in countries characterized by a stronger GDP growth rate. In a positive economic and dynamic economic environment, financial difficulties are easier to solve and, consequently, the forbearance measures may be an interesting and effective tool to overcome temporary issues. On the contrary-and quite surprisingly - the Strength to legal rights Index is not significant, from a statistical point of view, even though the regressor shows the expected sign.

The $R$-squared of the first regression, in Table 4 , is already very high, reaching the level of 86 per cent. Nonetheless, the explicative power of the regression increases further - to 90 percent — when we add the country dummies. Among these dummies, the two significant ones are Italy and Spain, with different signs. Italian banks use forbearance measures less that the other banks in the sample, whereas Spanish banks use them more. For Italy, the effect is above 4 percent and for Spain amounts to almost 3 percent. A potential explanation put forward by Homar et al. [20] refers to lax bank supervision. A stricter attitude of the Bank of Italy as opposed to a more flexible treatment of forborne positions by the Bank of Spain could explain why Italian banks refrain from negotiating concessions with borrowers in difficulties while Spanish banks make frequent use of this strategy. To support this hypothesis, Barth et al. [6] periodical survey on banking supervision around the world shows that, in the period 1999-2011, Italy increased largely both the index of supervisory powers and the index of external governance, whereas Spain remained unvaried on the first and tightened the second index, but to a lower extent than Italy.

Table 5 reports the results concerning the second research question. Once again, the variable NPL has strong explicative power and the expected sign. Banks with a higher burden of problematic assets not only tend to use more forbearance measures, but also classify the resulting positions more frequently into the non-performing category. However, the negative sign in the regressor FORBORNE shows that banks intensively using the instrument of forbearance classify a large share of the resulting forborne positions into performing category. To explore more in depth this aspect, in the second column, the equation includes an interaction term between NPL ratio and forborne ratio. The variable is strongly significant and has a negative sign. This means that, when both the burden of problematic loans are higher and the bank uses intensively forbearance measures, a lower percentage of forborne positions goes into the non-performing. The interpretation of this evidence suggests an opportunistic usage of the instrument of forbearance aimed at disguising the poor asset quality of the bank. This opportunistic behavior would intensify when the problem is more severe and the situation of the loan portfolio more deteriorated. 
Table 4 Determinants of the forborne positions' weight over total loans to non-financial corporations

\begin{tabular}{lll}
\hline C & 1.49 & -1.70 \\
NPL & $(0.19)$ & $(-0.13)$ \\
& $0.64^{* * *}$ & $0.64^{* * *}$ \\
LOG_ASSET & $(13.60)$ & $(12.55)$ \\
& 0.012 & $0.04^{*}$ \\
LOANS_SME & $(0.02)$ & $(0.07)$ \\
& 0.013 & 0.002 \\
Credit_protec & $(1.18)$ & $(0.26)$ \\
& 0.08 & -0.22 \\
Growth_gdp & $(0.39)$ & $(-1.08)$ \\
& $0.95^{* * *}$ & $0.99 * * *$ \\
SME_VA & $(5.48)$ & $(4.82)$ \\
& -0.06 & 0.006 \\
Italy & $(-0.76)$ & $(0.04)$ \\
& & $-4.40^{* * *}$ \\
Germany & & $(-3.18)$ \\
& & 1.35 \\
France & & $(1.60)$ \\
Spain & & -0.20 \\
Great Britain & & $(-0.22)$ \\
-squared & & $2.81^{* *}$ \\
Adjusted $R$-squared & & $(2.53)$ \\
Observations & & 1.27 \\
\hline
\end{tabular}

This table shows the results of estimating the following OLS regression: FORB $_{\text {RATIO }}=\beta_{0}+\beta_{1} \times$ NPL $_{\text {RATIO }}$ $+\beta_{2} \times \mathrm{LOG}_{\mathrm{LOANS}}+\beta_{3} \times \mathrm{SME}_{\mathrm{LOANS}}+\beta_{4} \times D_{\mathrm{COUNTRIES}}+\varepsilon \quad$ where the variables are defined as follows

FORB_RATIO:: percentage of exposures with an approved forbearance measure over the total carrying amount of loans to non-financial corporations, for each individual bank in the sample

NPL: percentage of exposures classified non-performing over the total carrying amount of loans to non-financial corporations, for each individual bank in the sample

LOG_ASSET: natural logarithm of total asset for each individual bank in the sample

LOANS_SME: percentage of loans to small and medium companies over the total carrying amount of loans to non-financial corporation, for each individual bank in the sample

GROWTH_GDP: 2016 growth rate if GDP in the country where the headquarters of the bank are located

SME_VA: 2016 percentage of values added produced by small and medium enterprises in the country where the headquarters of the bank are located

CREDIT_PROTEC: 2016 World Bank Strength of Legal Rights Index in the country where the headquarters of the bank are located

D_COUNTRIES (Italy, Germany, France, Spain and Great Britain): dummy variables whose value is equal to 1 if the individual bank is located in the country and 0 otherwise; $\varepsilon$ : assumed normally distributed error term with zero mean and constant variance

The $T$-statistics are in brackets under the estimated coefficients. *: two-tailed probability $<0.1$; **: two-tailed probability $<0.05$; $* * *$ : two-tailed probability $<0.01$
Table 5 Determinants of the forborne positions' classification in the non-performing category

\begin{tabular}{lll}
\hline $\mathrm{C}$ & $47.77 * * *$ & $31.56^{* * *}$ \\
$\mathrm{NPL}$ & $(7.38)$ & $(3.92)$ \\
& $1.32 * * *$ & $2.51^{* * *}$ \\
forborne & $(4.36)$ & $(4.80)$ \\
& $-1.042^{* * *}$ & -0.16 \\
NPL*FORB_RATIO & $(-2.11)$ & $(-0.25)$ \\
& & $-0.05^{* * *}$ \\
credit_protec & & $(-3.46)$ \\
& $2.12^{* * *}$ & $2.37 *$ \\
Italy & $(2.09)$ & $(2.28)$ \\
& & 0.02 \\
Germany & & $(0.002)$ \\
& & $22.33 * * *$ \\
France & & $(3.71)$ \\
& & 13.32 \\
Spain & & $(1.37)$ \\
& & 2.69 \\
Great Britain & & $(0.71)$ \\
& & 7.22 \\
-squared & & $(0.94)$ \\
Adjusted $R$-squared & & 0.35 \\
\hline
\end{tabular}

This table shows the results of estimating the following OLS regres-

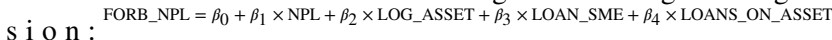
$+\beta_{5} \times \mathrm{NPL}$ RATIO $\times$ FORB RATIO $+\beta_{6} \times D_{\text {COUNTRIES }}+\varepsilon$

where the variables are defined as follows:

FORB_NPL: percentage of forborne positions classified as non-performing

NPL: percentage of exposures classified non-performing over the total carrying amount of loans to non-financial corporations, for each individual bank in the sample

NPL*FORBORNE: interaction term between NPL Ratio and Forborne ratio

CREDIT_PROTEC: 2016 World Bank Strength of Legal Rights Index in the country where the headquarters of the bank are located

D_COUNTRIES (Italy, Germany, France, Spain and Great Britain): dummy variables whose value is equal to 1 if the individual bank is located in the country and 0 otherwise; $\varepsilon$ : assumed normally distributed error term with zero mean and constant variance

The $T$-statistics are in brackets under the estimated coefficients. *twotailed probability $<0.1$; **two-tailed probability $<0.05$; $* * *$ twotailed probability $<0.01$

Looking at the country dummies, in this case the only significant one is Germany where, apparently, the percentage of forborne positions classified as non-performing is significantly higher than elsewhere. The Strength of legal right Index is significant and positively associated with the share of forborne positions classified as non-performing in both specifications.

Table 6 reports the results concerning the third research questions, i.e., the determinants of the impairment level of forborne positions. In a nutshell, we could summarize 
Table 6 Determinants of the impairment level of forborne positions

\begin{tabular}{ll}
\hline C & 0.12 \\
& $(0.59)$ \\
& $0.39^{* * *}$ \\
CORB_NPL & $(6.75)$ \\
& $-0.26^{* * *}$ \\
& $(-4.34)$ \\
LOANS_SME & $0.12^{* * *}$ \\
& $(2.42)$ \\
CREDIT_PROTEC & -0.003 \\
& $(-0.5)$ \\
-squared & 0.62 \\
Adjusted $R$-squared & 0.58 \\
Observations & 105 \\
\hline
\end{tabular}

This table shows the results of estimating the following

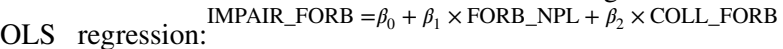
$+\beta_{3} \times$ LOANS_SME $+\beta_{4} \times D_{-}$COUNTRIES

where the variables are defined as follows:

IMPAIR_FORB: percentage impairment over the total carrying amount of loans to non-financial corporations with approved forbearance measures, for each individual bank in the sample

FORB_NPL: percentage of forborne positions classified as non-performing

COLL_FORB: collateral assisting forborne positions in percentage of their total carrying amount

LOANS_SME: percentage of loans to small and medium companies over the total carrying amount of loans to non-financial corporation, for each individual bank in the sample

The $T$-statistics are in brackets under the estimated coefficients. *twotailed probability $<0.1$; **two-tailed probability $<0.05$; $* * *$ twotailed probability $<0.01$

by saying: nothing new under the sun. The coverage level is higher when the forborne position is classified as nonperforming, thus indicating a more severe situation of financial distress. The average impairment level is higher in banks having a credit portfolio more tilted toward small and medium enterprises, since the expected recovery is lower for this kind of exposures. The impairment level is lower when the positions are covered more extensively with valuable collateral. The macroeconomic controls and the country dummies-unreported in Table 6 for the sake of space-are all statistically insignificant. The only surprise is the Strength of legal right index that does not appear to be associated with the impairment level. The level of credit protection seems to bear more on the kind of workout strategy chosen, more than on the forecast of potential loss given default.

\section{Conclusions}

The paper focuses on the usage of forbearance measures, on the classification of the resulting forborne positions and on their loan loss provisioning, based on the dataset of the
EU-wide Transparency Exercise carried out by the European Banking Authority on a sample of 130 major banking institutions.

The analysis confirms that forbearance measures are a tool frequently used by European banks. More than a precautionary instrument to prevent default, these measures represent a strategy to manage the non-performing portfolio. In fact, a strong statistical correlation emerges between the NPL ratio and the weight of forborne exposures. In terms of localization, Italian banks tend to use forbearance less and Spanish banks more than the rest of the sample. A potential explanation could lay in the different severity of local Supervisory Authorities.

The analysis concerning the credit classification of forborne positions suggests an opportunistic usage of the instrument of forbearance aimed at disguising the poor asset quality of the bank. In particular, this opportunistic behavior tends to intensify when the problem is more severe and the situation of the loan portfolio more deteriorated.

In terms of provisioning, no particular criticalities emerge. The impairment level is higher when a larger share of forborne exposures is classified non-performing, whereas it is lower when these positions are well collateralized.

Funding Open access funding provided by Università degli Studi di Torino within the CRUI-CARE Agreement.

Open Access This article is licensed under a Creative Commons Attribution 4.0 International License, which permits use, sharing, adaptation, distribution and reproduction in any medium or format, as long as you give appropriate credit to the original author(s) and the source, provide a link to the Creative Commons licence, and indicate if changes were made. The images or other third party material in this article are included in the article's Creative Commons licence, unless indicated otherwise in a credit line to the material. If material is not included in the article's Creative Commons licence and your intended use is not permitted by statutory regulation or exceeds the permitted use, you will need to obtain permission directly from the copyright holder. To view a copy of this licence, visit http://creativecommons.org/licenses/by/4.0/.

\section{References}

1. Adalet McGowan, M., D. Andrews and V. Millot, 2017. The Walking Dead?: Zombie Firms and Productivity Performance in OECD Countries, OECD Economics Department Working Papers, No. 1372, OECD Publishing.

2. Ahearno, A.G., and N. Shinada. 2005. Zombie firms and economic stagnation in Japan. International Economics and Economic Policy 2 (4): 363-381.

3. Andrews, D., Petroulakis, F. 2019. Breaking the Shackles: Zombie Firms, Weak Banks and Depressed Restructuring in Europe, ECB Working Paper No. 2240.

4. Banerjee, R., Hofmann, B. 2018. The rise of zombie firms: Causes and consequences, BIS Quarterly Review. 
5. Bank for International Settlements. 2016. Prudential treatment of problem assets - definitions of non-performing exposures and forbearance

6. Barth J.R., Caprio G., Levine R. 2013. Bank Regulation and Supervision in 180 Countries from 1999 to 2011, NBER Working Paper n. 18733.

7. Basel Committee on Banking Supervision, Guidance on credit risk and accounting for expected credit losses, December 2015.

8. Basel Committee on Banking Supervision, Prudential treatment of problem assets-definitions of non-performing exposures and forbearance, July 2016.

9. Bruche, M., and G. Lllobet. 2014. Preventing zombie lending. Review of Financial Studies 27: 923-956.

10. Caballero, R.J., T. Hoshi, and K. Kashyap. 2008. Zombie lending and depressed restructuring in Japan. American Economic Review 98: 1943-1977.

11. European Banking Authority, Draft guidelines on credit institutions' credit risk management practices and accounting for expected credit losses, July 2016.

12. European Banking Authority, Draft regulatory technical standards on the materiality threshold for credit obligations past due under Article 178 of Regulation EU n. 575/2013, September 2016.

13. European Banking Authority, Final draft Implementing Technical Standards. On supervisory reporting on forbearance and nonperforming exposures under Article 99(4) of Regulation EU $n$. 575/2013, September 2016.

14. European Banking Authority, Guidelines on the application of the definition of default under Article 178 of Regulation EU $n$. 575/2013, September 2016.

15. European Banking Authority, Report on the dynamics and drivers on non-performing exposures in the EU banking sector, July 2016.
16. European Banking Authority, Results from data collection exercise on the proposed regulatory changes for a common EU approach to the definition of default, September 2016.

17. European Central Bank, Addendum to the ECB Guidance to banks on non-performing loans: Supervisor expectations for prudential provision for non-performing exposures, March 2018.

18. European Central Bank, Guidance to banks on non-performing loans, March 2017.

19. European Central Bank, Stocktake of national supervisory practices and legal frameworks related to NPLs, September 2016.

20. Homar T., Kick H., Salleo C. 2015. What drives forbearance: evidence from ECB Comprehensive Assessment, ECB Working Papers n. 1860.

21. Klees, S.J. 2016. Inferences from regression analysis: are they valid? Real-World Economics Review 74: 85-97.

22. Nkusu M. 2011. Non-performing loans and macrofinancial vulnerabilities in advanced economies, IMF Working Paper 11/161.

23. Pagano, M. 2014 Lessons from the European Financial Crisis, CFS Working Paper No. 486.

24. Storz, M., Koetter, M., Setzer, R., Westphal, A. 2017. Do We Want These Two to Tango? On Zombie Firms and Stressed Banks in Europe, ECB Working Paper No. 2104.

Publisher's Note Springer Nature remains neutral with regard to jurisdictional claims in published maps and institutional affiliations.

Paola De Vincentiis is full professor of Banking and Financial Markets at the University of Torino. She is also vice-Dean of the Department of Management and member of Group of Experts in Valuation (GEV) at the National Agency for Research Valuation (ANVUR). 